\title{
EXPERIMENTAL AND NUMERICAL ANALYSIS OF MICRO-SCALE HEAT TRANSFER USING GRAPHENE NANOFLUID IN MICROCHANNELS FOR ENHANCED THERMAL PERFORMANCE
}

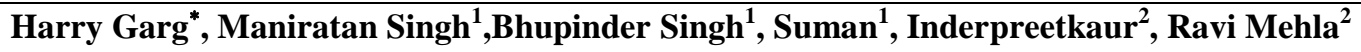 \\ Central scientific instruments organization(CSIR-CSIO) \\ Chandigarh, India \\ *Corresponding Author-harrygargcsio@outlook.com
}

\begin{abstract}
:-
Heat transfer and thermal management is the key factor in the miniaturized systems. About 50\% of energy is waste in the thermal management system and effect the reliability and performance of the devices. The existing heat transfer technologies suffer from numerous limitations and are poor in high performance and high heat dissipation. Liquid cooling using microchannels and nanofluids work with the increased surface area and minimum thermal resistance. The high thermal gradient and development of thermal boundary layer increases the heat transfer. The thermal boundary layer variation is achieved by varying geometrical and fluid parameters. Three different shapes of microchannelsi.e rectangular, curved \& triangular microchannel are considered. The standard flow arrangement and the uniform aspect ratio of the plenum are considered for different parametric analysis and comparisons. The aspect ratio of the micro-channels has been varied and the study was carried out at three different aspect ratios (Height/Width). Graphene based nanofluid as heat carrier fluid from microchannel has been used. The thermal boundary layer variation for different parameters areanalysed. The system has reported high heat transfer coefficient and high thermal conductivity. The proposed fluid almost interacts as another solid and has reduced thermal resistance and thus almost vanishing high hot spots. The heat transfer coefficient of $10000 \mathrm{~W} / \mathrm{m}^{2} \mathrm{~K}$ has been achieved. The proposed work overcomes the limitations of the existing technologies and has high thermal performance. Experimental analysis shows that the proposed Nano fluid is the excellent fluid for high rate heat removal. Moreover the performance of the overall system is excellent in terms of high heat transfer coefficient, thermal conductivity and heat capacity of the fluid. It has been reported that the heat transfer coefficient can be increased by 6 to $\mathbf{1 0}$ times of the water for any other fluid in the present scenario.
\end{abstract}

I. INTRODUCTION

Keywords-Microchannel, Nusselt no., Heat transfer coefficient, Nanofluids
In previous few decades there has been unprecedented growth in the field of high performance computing, electronic and communication technologies. Due to maximum operation like storage data and miniaturization of computer and electronic devices thermal management have become serious problem basically in case of Laser machine, X-Ray, Optical fibres, LED and many devices which is widely used in today's computation. Hence, heat dissipation rate is also increasing due to which cooling of electronic devices became very significant to aggrandize the performance of systems. Now there become an objective to enhance cooling system and increase power by using compact size heat sink and high performance coolant which provide an innovative research field. Not only miniature electronic devices need cooling but large transportation trucks and fuel cells also require efficient and high capacity cooling systems. Many conventional fluids are used for the purpose of cooling in such type of devices i.e water, ethylene glycol, pump oil and transfer oil. Suspension of Nanoparticles in the liquid media making colloidal mixture called Nanofluids which have been studied world wide due to inconsistent thermal behavior of fluids. Basically Nanoparticles are nanometer sized particles $\left(\mathrm{Al}_{2} \mathrm{O}_{3}, \mathrm{Fe}, \mathrm{CuO}, \mathrm{TiC}, \mathrm{Ag}, \mathrm{Au}\right)$ which helps to increase the efficiency of base fluids due to their significant features like large surface area, higher mobility \& stability, reduced pumping power \&less chances of erosion. Nanofluids as well as the microchannels plays important role in heat dissipation. Due to flow of nanoparticles from microchannels there is very high heat transfer rate and surface area Due to there nanosize they do not clog inside the channels like micrometer or micrometer sized particles. In the past decade there have been developed variety of methods and techniques which are capable to produce nanometer sized particles which helps in pioneering engineering application and scientific study world wide. With the advancement of modern nanotechnology the size of nanomaterial which are produced is $<50 \mathrm{~nm}$. The size of solid nanoparticles is 
typically of (1-100nm) which dispersed into the base fluid. A small amount ( $<1 \%$ volume fraction) of $\mathrm{Cu}$ nanoparticles on carbon nanotubes which gets dispersed into base fluid (Ethylene Glycol or Oil) is reported to increase the thermal conductivity of liquid by $40 \%$ and $50 \%$ respectively[1].There are different types of nanomaterial used are Spherical, Cylindrical, Disk Shaped and Fractal shaped nanoparticles[ $\left.{ }^{2}\right]$. Nanofluids posses the properties as:-

- Higher thermal conductivity - Due to presence of large surface area of nanoparticles there is versed impact on heat transfer rate. Size of nanoparticles from 10um-20um is such that they behave like molecules. Hence, there surface contains atoms which performs thermal interaction. It have been investigated that with the rise of temperature there will increase in heat transfer rate.

- Mobility - Due to very tiny size of nanoparticles almost 10um-20um particles shows greater mobility which enhanced heat transfer rate and maintain the Newtonian behaviour of fluids.

- Stability- As compared to micrometer sized particles nanoparticles are higher stable in nature due to small size. Hence, the sedimentation will also reduced due to less weight of nanoparticles which overcome the problem of stability in micrometer sized particles. Stability can also improved by using stabilizing agent. Nanofluids shows unprecedented stability and high thermal conductivity when there will low volume fraction of nanoparticles $\left[{ }^{\mathrm{i}}\right]$.

- Ideal for microchannel Application- Due to flow of nanoparticles from microchannels there is very high heat transfer rate and surface area. Due to therenanosize they do not clog inside the channels like micrometer or macrometersizd particles.

- Reduced chances of erosion- Due to very small size of nanoparticles the impact the cause on surface or wall is very small that the erosion rate reduced in microchannel, pumps, heat pipes...etc.

- Deduction in pumping power - It also depends upon the viscosity of nanofluids when there is high volume ratio of Nanoparticles then viscosity rate will also high. Hence, there will increase in pumping power. We can decrease pumping power when there is very less volume fraction of nanoparticles.
- Significance of particle size:- it have been investigated that with the decrease of particle size there is enhancement in heat transfer rate. Hence, not only particle concentration maters but particle size also matters.

Also due to the miniaturization of electronic devices there have been large heat dissipation rates [3]. So for the thermal management of electronic component there have been wide applications of microchannels. Now the question arises to study the behaviour of flow of nanofluids and heat transfer coefficient in microchannels which can be further used to optimize the heat sinks which can be very useful for the development of new technology. Starting the thermal conductivity from Aluminium, Copper, Silver, Diamond upto carbon nanotubes ( Multiwalled carbon nanotubes) there is enhancement in thermal conductivity upto 2000 times then engine oil[4].The heat transfer coefficients of both nanofluidsand pure water at low Reynolds numbers are practically higher than those acquired at high Reynolds number in generally vast microchannels, which demonstrates the heat transfer qualities of microchannels [5]. So, Microchannel miniaturized cooling system device can be successfully utilized for cooling of such systems. Tuckerman et al[6] first time fabricated the microchannel ( $\mathrm{W}_{\mathrm{W}}=\mathrm{W}_{\mathrm{c}} 57 \mu \mathrm{m}$ and $\left.\mathrm{z}=365 \mu \mathrm{m}\right)$ and circulate the water into it which solved the problem of cooling the VLSI circuits with maximum heat dissipation rate of $7.9 \mathrm{MW} / \mathrm{m}^{2}$. Microchannel provides larger surface area to volume ratio, and very high heat transfer coefficient. Lot of work has been done on the fabrication on the microchannel till today. VikasYadav et al [7] fabricated the upstream finned microchannel with low Reynolds number which result heat transfer

of $160 \%$ with low pressure drop as compared to downstream finned microchannel and complete finned microchannel. Phillips[8] analysed Heat transfer and fluid flow process in microchannels which provided equations which become helpful in designing microchannel geometries. By integration of Microchannel system with high capacity nanofluid like CNT, Graphene it tends to carried away considerable amount of heat and can further circulate in a cycle for continues operation. Graphene is the most useful carbon material for making the nanofluid due to their high thermal conductivity; The thermal conductivity of this is in the range of $3000-5000 \mathrm{~W} / \mathrm{m}-\mathrm{K}$; is high due to radial phonon transport in graphene[9]; In recent years, a significant number of studies have been conducted on graphene due to its unique thermal, electrical, optical, mechanical andother relevant 
characteristics[10].Graphene based nano-suspensions called Nanofluids have shown great potential to be the next generation of smart fluids. These nanofluids are prepared by dispersing properly functionalized. Graphene in fluids such as water, ethylene glycol, oils etc[11]. The suspensions show excellent thermal transport properties with $\sim 10-100 \%$ increase in the thermal conductivity of the fluid and similar augmentation in forced convective heat transfer coefficients. They behave as 'smart' fluids and conduct more heat with increasing temperature. Now the question arises to study the behavior of flow of nanofluids and heat transfer coefficient in microchannels which can be further used to optimize the heat sinks which can be very useful for the development of new technology[12].Suspension of Nanoparticle in the liquid media making colloidal mixture called Nanofluids which have been studied world wide due to anomalous thermal behavior of fluids. Due to these particle concentration it shows enhanced thermal conductivity where as micrometer sized particles shows no such enhancement hence nanofluids retain excellence characteristics of enhancing heat transfer rate[13]. The heat transfer coefficients of both nanofluids and pure water at low Reynolds numbers are practically higher than those acquired at high Reynolds number in generally vast microchannels, which demonstrates the heat transfer qualities of microchannels[14].

\section{GEOMETRY CONSIDERATION}

\section{A.Microchannel Design}

In our purposed geometrical configuration i.e Rectangular, Curved and Triangular microchannel made up of copper material are considered. Copper material had been utilized because of high thermal conductivity in the scope of metals. Copper indicates thermal conductivity of 385 $\mathrm{K}(\mathrm{w} / \mathrm{mk})$ at room temperature of $25^{\circ} \mathrm{C}$. Table 1 shows the physical parameters i.e, length, width, height $\&$ no. of channels of our designed microchannels. Graphene nanofluids are prepared by two step method in which DI is used as host fluid and graphene oxide as the dispersed nanoparticles. GO is prepared from carboxylation method with $\mathrm{H}_{2} \mathrm{SO}_{4}$ and $\mathrm{HNO}_{3}$ composition[15]. Graphene based nanofluids have been used with varying micro concentrations $(0.005 \%-0.001 \%)$.
TABLE I. DIFFERENT PARAMETERS OF VARIOUS GEOMETRY

\begin{tabular}{|c|c|c|c|c|c|}
\hline $\begin{array}{l}\text { Sr.n } \\
\text { o }\end{array}$ & $\begin{array}{l}\text { Microchann } \\
\text { el }\end{array}$ & $\begin{array}{l}\text { Lengt } \\
\mathrm{h}\end{array}$ & $\begin{array}{l}\text { Widt } \\
\text { h }\end{array}$ & $\begin{array}{l}\text { Heig } \\
\text { ht }\end{array}$ & $\begin{array}{l}\text { No. of } \\
\text { Channe } \\
\text { ls }\end{array}$ \\
\hline 1. & $\underline{\text { Rectangular }}$ & $\begin{array}{l}15- \\
22 \mathrm{~mm}\end{array}$ & $\begin{array}{l}0.5- \\
1 \mathrm{~mm}\end{array}$ & $\begin{array}{l}2- \\
7 \mathrm{~mm}\end{array}$ & 14 \\
\hline 2. & $\frac{\text { Triangular }}{\text { Downstream }}$ & $\begin{array}{l}15- \\
22 \mathrm{~mm}\end{array}$ & $\begin{array}{l}0.5- \\
1 \mathrm{~mm}\end{array}$ & $\begin{array}{l}2- \\
7 \mathrm{~mm}\end{array}$ & 14 \\
\hline 3. & $\frac{\text { Triangular }}{\underline{\text { Upstream }}}$ & $\begin{array}{l}15- \\
22 \mathrm{~mm}\end{array}$ & $\begin{array}{l}0.5- \\
1 \mathrm{~mm}\end{array}$ & $\begin{array}{l}2- \\
7 \mathrm{~mm}\end{array}$ & 14 \\
\hline
\end{tabular}

\section{B. Experimental Setup and Procedure}

A schematic of the experimental facility utilized as a part of this Investigation in which Deionized water and Graphene based nanofluid from a holding tank is driven through the flow loop utilizing peristaltic pump. This methodology was observed to be desirable over the utilization of a pump, and provided smooth and enduring stream up an extensive variety of flow rates. The liquid then finishes through a microchannel test area.The microchannels were cut utilizing a Wire EDM machine.Three such test pieces were created with microchannels of various widths, height and length. Table 1 records the microchannel measurements in each of the fabricated test pieces. Holes were drilled into the base of the copper piece to house four cartridge radiators that can provide a combined maximum power of $100 \mathrm{~W}$. Three (Type-K) thermocouples were inserted in the copper test segment. The temperature readings from these thermocouples are extrapolated to give the normal average microchannel wall temperature. Type $\mathrm{k}$ thermocouples were additionally situated at the inlet and outlet of the test area to measure the liquid temperatures at these areas. All thermocouples were read into a data acquisition system. The voltage input to the cartridge heaters was controlled by a DC power supply unit. 
Asia Pacific Journals

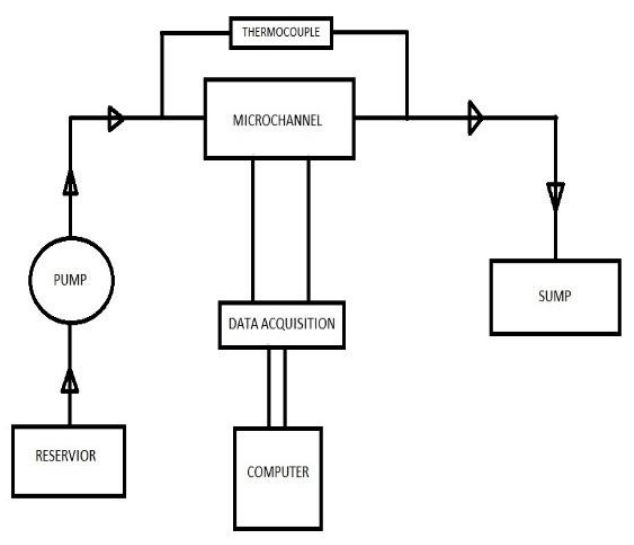

FIGURE 2: SCHEMATIC OF THE EXPERIMENTAL APPARATUS.

\section{SIMULATION WITH COMSOL MULTIPHYSICS}

The Microchannels has been design and simulated with the Structural mechanics physics of the MEMS Tool: COMSOL. Three different shapes with varying dimensions of microchannel has been used to get the optimized result and Graphene based nanofluid was used as heat carrier fluid. The output of the different shapes has been studied on the basis of the various velocities of nanofluids with different concentration rate of nanomaterial. The local convective heat transfer coefficient and the corresponding Nusselt number along the channel were obtained from the Newton's cooling law[16].The proposed design was simulated after completing the system with Physics control meshing as shown in FIGURE 3.

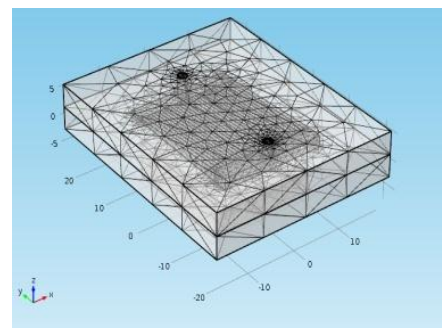

(a)

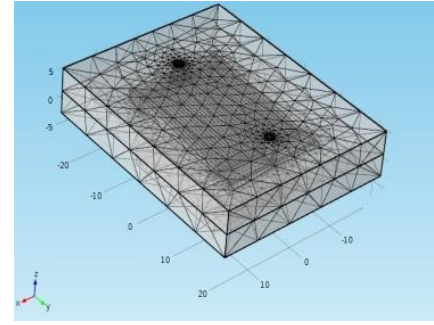

(b)

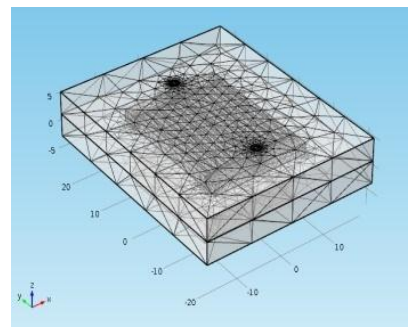

(c)

FIGURE 3: MESHED MICROCHANNEL DESIGN (a)UPSTREAM TRIANGULAR (b)DOWNSTREAM TRIANGULAR (c)RECTANGULAR

The estimated liquid temperatures along the channel with the measured wall temperature data along the channel and liquid temperatures at the inlet and outlet are calculated as[10]

$$
\begin{gathered}
\mathrm{h}=-\left(\mathrm{k} / \mathrm{T}_{\mathrm{S}}-\mathrm{T}_{\mathrm{V}}\right)(\mathrm{dt} / \mathrm{dx}) \\
\mathrm{Nu}=\mathrm{hD}_{\mathrm{h}} / \mathrm{k} \\
\mathrm{D}_{\mathrm{h}}=\text { Area/ wetted perimeter } \\
\text { Area }=4 * \text { height of channel*width of channel }
\end{gathered}
$$

Wetted perimeter $=2 *$ height of channel + width of channel

The rate of convection heat transfer is observed to be proportional to the temperature difference \& is conveniently expressed by Newton's Law of cooling as:-

$$
\text { Qconv }=\mathrm{h}\left(\mathrm{T}_{\mathrm{S}}-\mathrm{T}_{\infty}\right)
$$

The Navier Stokes Equations for laminar fluid flow through channels are represented as follows:-

Continuity equation :- 


$$
\rho C p \mu . \nabla T=\nabla \cdot(k \nabla T)+Q
$$

Equation for heat transfer in solids:-

$$
\begin{gathered}
\rho(u \cdot \nabla)=\nabla \cdot\left[-\rho l+\mu\left(\nabla \mu+(\nabla \mu)^{\mathrm{T}}\right)-\right. \\
2 / 3 \mu(\nabla \cdot \mu) l]+F \\
\nabla \cdot(\rho \mu)=0
\end{gathered}
$$

The analysis is based on the following assumptions:-

- Steady state flow.

- Incompressible fluid.

- Laminar flow.

- Constant properties of both fluids and solid.

- Effects of viscous dissipation are negligible.

The effective thermal conductivities of nanofluids of Graphene suspended in DI water turned out to increase linearly with the volume fraction of the oxide particles in the host liquids.

\section{RESULT AND DISCUSSIONS}

Three different microchannel with nanofluid has been studied and simulated within the COMSOL including copper as base material. Following results shows heat transfer coefficient and Nusslet no. for nanofluids with various volume fractions of nanoparticle and pure water in various shapes of microchannel. Maximum enhancement is observed in the graphene nanofluids with $0.005 \%$ volume concentration and upstream triangular design of microchannels. When we use the water in diiferent shapes of microchannels the observed data shows that as the length of channel increases the heat transfer also increases and it is max. in the case of rectangular geometry But the study with of grapheme nanofluid is not same \& Heat transfer coefficient is maximum at minimum length of upstream triangular geometry channel.

A. Comparison of heat transfer coefficient with different parameters:-

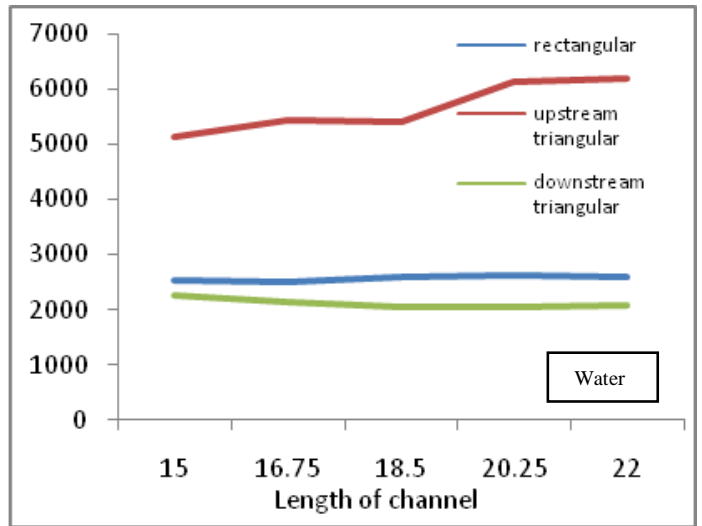

(a)

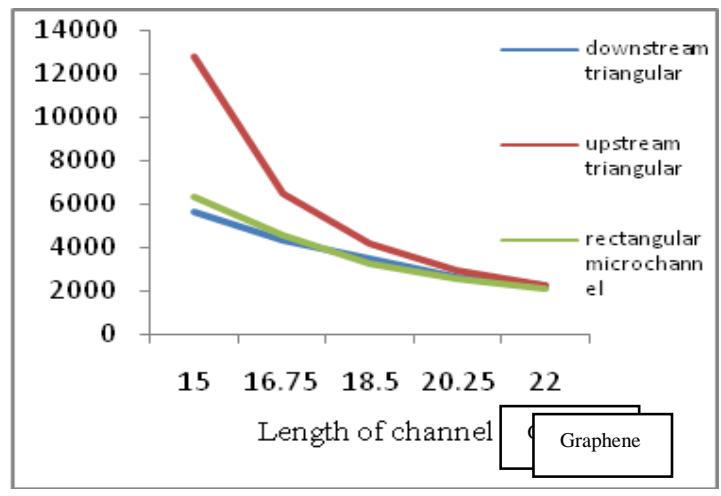

(b)

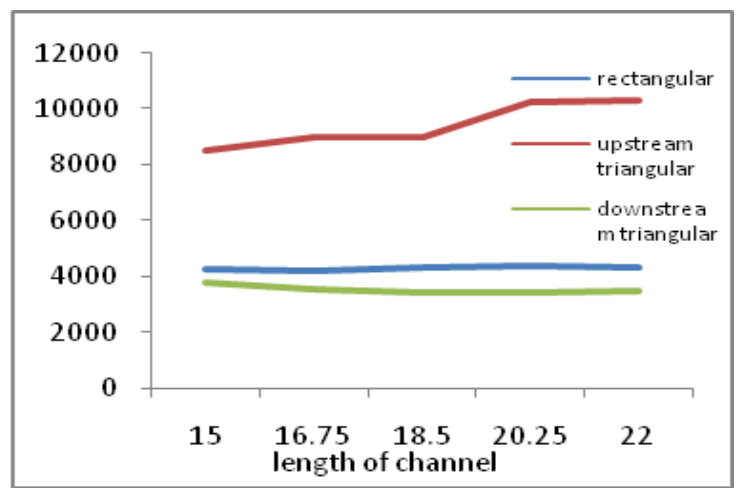

(c)

FIGURE. 3 EFFECT OF LENGTH ON HEAT TRANSFER COEFFICIENT FOR DIFFERENT DESIGNS OF MICROCHANNELS(a) WATER (b)GRAPHENE WITH 0.005 VOL.\% (c)GRAPHENE WITH 0.001 VOL.\% 


\section{Asia Pacific Journals}

B. Effect on Nusslet number

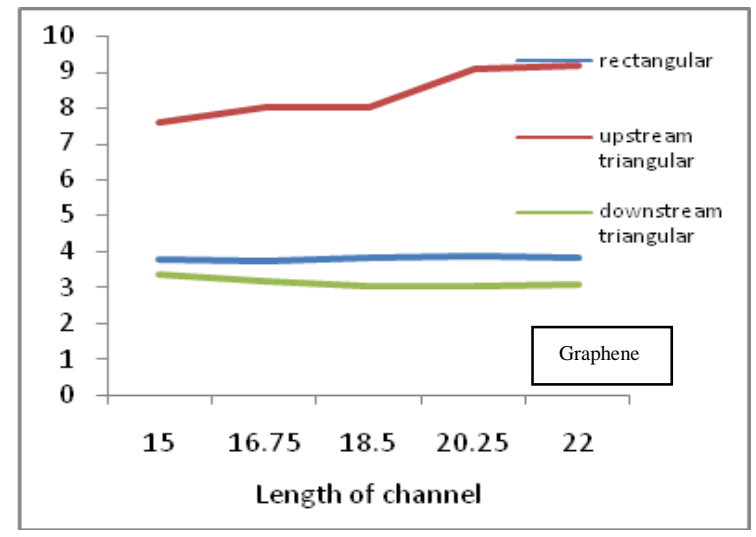

(a)

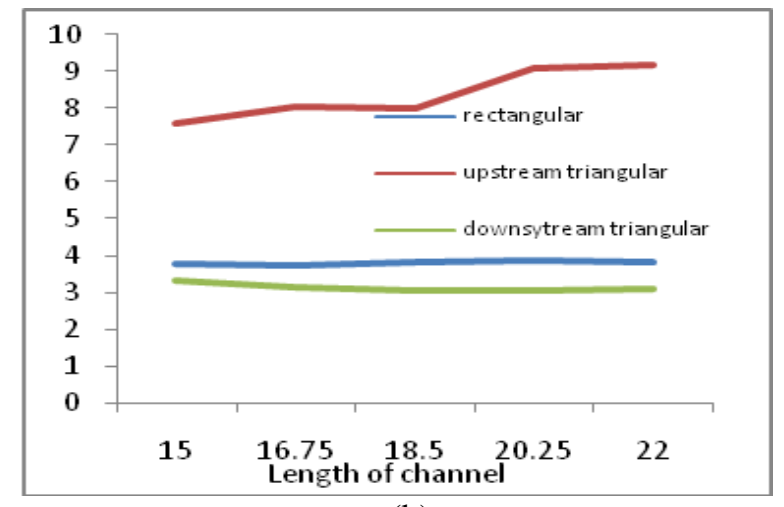

(b)

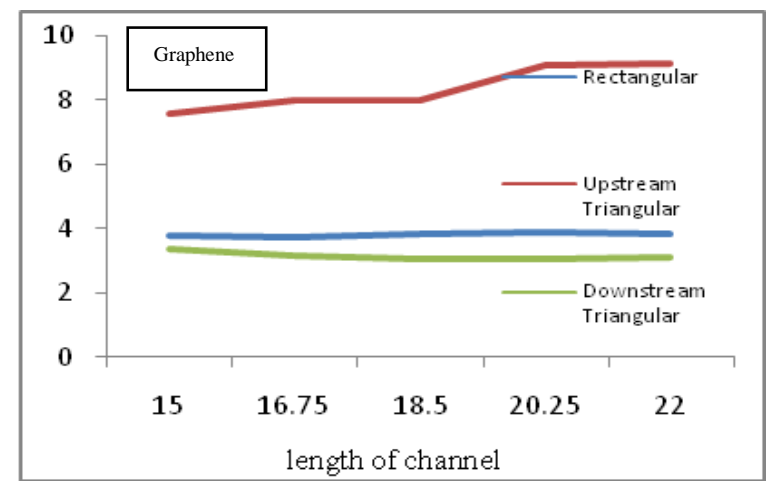

(c)

FIGURE 4 EFFECT OF MICROCHANNEL LENGTH ON NUSSLET NO. (a)WATER (b) GRAPHENE $(0.005 \%)$ (c)GRAPHENE $(0.001 \%)$

\section{CONCLUSIONS}

Nusselt no. and heat transfer coefficient ofgraphene nanofluids was investigated with the help of diverse shapes of microchannels i.e, rectangular, Upstream triangular, downstream triangular. The heat transfer coefficient increased in the case grapheme nanofluids with higher concentration as compared to water with upstream triangular shape. There is change in the nusselt no. with respect to length of channel also increase in Reynolds number.

\section{ACKNOWLEDGEMENT:}

The authors are thankful to Director, CSIR and CSIO for providing the necessary facilities for the research work carried out.

Nomenclature

\begin{tabular}{|c|c|}
\hline \multicolumn{2}{|c|}{ Units \& Their Meanings } \\
\hline$h$ & Heat transfer coefficient \\
\hline$T_{v}$ & Volume temperature \\
\hline$T_{s}$ & Surface temperature \\
\hline$N u$ & Nusslet number \\
\hline$D_{h}$ & Hydrodynamic diameter \\
\hline $\mathrm{k}$ & Thermal conductivity \\
\hline $\mathrm{qconv}\left(\mathrm{W} / \mathrm{m}^{2}\right)$ & \\
\hline$\left(\mathrm{W} / \mathrm{m}^{2} \mathrm{~K}\right)$ & Heat transfer coefficient \\
\hline
\end{tabular}




\section{REFERENCES}

[1] Eastman, Choi, S. U. S, "Enhancing thermal conductivity of fluid with nanoparticles", Appl. Phys. Lett.vol.78 (6), 718, 1995.

[2] Choi, S. U. S, S. Li, W.Yu and L. J.Thompson, "Anomalously increased effective thermal conductivities of ethylene glycol-based nanofluids containing copper nanoparticles", Appl. Phys. Lett. 79 (14), 2252, 2001.

[3] M.B.Akgiil and M. Pakdemirli, " Numerical analysis of mixed convection of nanofluids inside a vertical channel ", Int. J. computational methods, vol.13, 1650012 1-11, 2015.

[4] Sarit Kumar Das, Stephen U.S. Choi, Hrishikesh E. Patel,"Heat transfer in Nanofluids", Heat transfer engineering, vol.27(10), pp.3-19, 2008.

[5] Jung-Yeul Jung, Hoo-Suk Oh, Ho-Young Kwak, "Forced convective heat transfer of nanofluids in microchannels", International Journal of Heat and Mass Transfer, vol. 52, pp.466-472, (2009).

[6] D.B. Tuckerman, R.F.W. Pease, " High performance heat sinking for VLSI”, IEEE electron device letter, vol. EDL-2, pp.5,1981.

[7] VikasYadav, KuldeepBaghel, Ritunesh Kumar, S.T. Kadam, “ Numerical investigation of heat transfer in extended surface"Int. J. heat and mass transfer, vol.93, pp. 612,2015.

[8] Richard J.Phillips "Microchannel heat sinks",Linkon Laboratory Journal, vol 1, no.1,1988.

[9] Wei Yu, Huaqing Xie, Xiaoping Wang, Xinwei Wang, "Significant thermal conductivity enhancement for nanofluids containing graphene nanosheets", Physics Letters A, vol.375,pp.1323-1328, 2011
[10] Hossein Akhavan-Zanjani, Majid Saffar-Avval, Mohsen Mansourkiaei, Farhad Sharif, Mohammad Ahadi, "Experimental investigation of laminar forced convective heat transfer of Graphene water nanofluid inside a circular tube", International Joumal of Thermal Sciences, vol. 100, pp.316-323, 2016.

[11] Experimental Investigation on Thermal Performance of KeroseneGraphene Nanofluid, "Deepak Kumar Agarwal, Aravind Vaidyanathan, S. Sunil Kumar", Experimental Thermal and Fluid Science, vol.15, pp. S0894-1777, 2015.

[12] Choi, S. U. S, S. Li, W.Yu and L. J.Thompson, "Anomalously increased effective thermal conductivities of ethylene glycol-based nanofluids containing copper nanoparticles", Appl. Phys. Lett. 79 (14), 2252,2001

[13] Samir Hassani, R. Saidur, SaadMekhilef, ArifHepbasli, "A new correlation for predicting the thermal conductivity of nanofluids using dimensional analysis", Int. J. Heat and Mass Transfer vol.90,pp.121-130, 2015 .

[14] Jung-Yeul Jung, Hoo-Suk Oh, Ho-Young Kwak, "Forced convective heat transfer of nanofluids in microchannels", International Journal of Heat and Mass Transfer, vol. 52, pp.466-472, (2009).

[15] I.A. Stogiannis, A.A. Mouza, S.V. Paras, "Efficacy of SiO2 nanofluids in a miniature plate heat exchanger with undulated surface", Int. J. Thermal Sciences vol.92, pp.230-238, 2015.

[16] Samir Hassani, R. Saidur, SaadMekhilef, ArifHepbasli, "A new correlation for predicting the thermal conductivity of nanofluids using dimensional analysis", Int. J. Heat and Mass Transfer vol.90, pp.121-130, 2015. 